\title{
NEW PHYSICS LABORATORIES AT UNIVERSITY COLLEGE, LONDON
}

\begin{abstract}
THE new Physics Wing at University College, London, was officially opened on May 4 by Sir James Chadwick, in the presence of some five hundred guests widely representative of the scientific, industrial and teaching life of the community.

The opening of this new building marks the completion of the first stage in the provision of permanent accommodation for the Physics Department after the destruction suffered during the Second World War. It provides something less than half the floor space which, it is envisaged, will eventually be made available to the Department.

The building, which has six floors, was designed by Prof. A. E. Richardson and built by Messrs. Dove Bros., Ltd. It is of steel frame construction faced mainly with Kentish stock brickwork, but has Portland stone up to the ground-floor level and stone dressings around the windows. The roof is of concrete, insulated with cork and covered with copper. In order to save the cost of periodical repairs, the window sashes are constructed of aluminium, specially treated to resist corrosion. Invisible steam pipes embedded in the ceilings provide heat for the building. Three rows of steel channel inserts fixed flush to the surface of all available wall space provide ready means for suspension and temporary fitting of apparatus.
\end{abstract}

Three of the six floors are devoted mainly to research, and the remaining three floors to teaching laboratories. These undergraduate laboratories, situated on the first, second and third floors, can accommodate all the undergraduate practical training, except for an elementary class still housed in an older part of the College. Accommodation is provided for about thirty-five students in each of the three years of the course for the B.Sc. (Special) degree in physics as well as for a somewhat larger number of students who take a two-year course in physics ancillary to chemistry or astronomy. A number of students reading physics for the B.Sc. (General) degree are also accommodated.

Each of the undergraduate laboratories occupies a floor space of 4,600 sq. ft. and includes dark rooms for optical experiments, extensive apparatus stores and technicians' rooms. In addition, there are fully equipped photographic dark rooms, a balance room, and workshop facilities for the use of undergraduate students. There are some sixty or seventy student benches in each laboratory, and points for gas, water and electrical power are liberally distributed.

Particular care has been taken with the design of facilities for the third-year student laboratory. It has been the custom at University College for several years now to encourage third-year undergraduate students of experimental physics to develop their originality by tackling more elaborate experiments than they have attempted previously. 'They are given small experimental projects in which they gain experience in the design and construction of apparatus and in solving problems relating to its working. While these experiments cover a wide range of topics, considerable emphasis is placed on electronics.

It is interesting to recall that the first courses in practical physics arranged for undergraduate students in any English university were given at University
College in the session $1866-67$ on the initiative of Prof. Carey Foster. The new teaching laboratories should provide adequate facilities to enable the traditions of the College in the teaching of practical physics to be worthily maintained.

Turning now to the research facilities provided by the new building, these are housed on the lower ground floor, the ground floor and the fourth floor.

The lower ground floor has a ceiling $16 \mathrm{ft} .6 \mathrm{in}$. high, and the greater part of the floor is occupied by the electron accelerator laboratory, which extends along the whole length of the floor and over about two-thirds of the width. An overhead travelling crane runs the full length of this laboratory, which is at present divided into three rooms by temporary partitions.

A microtron (electron cyclotron) accelerator producing a mean extracted current of 0.5 pamp. of electrons at $5 \mathrm{MeV}$. energy has been constructed and is in full operation. A larger microtron to provide $25-\mathrm{MeV}$. electrons is under construction and will also be installed on the lower ground floor. Both these machines are to be used in an extensive study (already in progress) of fast-electron scattering by nuclei.

The lower ground floor also houses a store, glassblowing shop, daxk rooms, a spectroscopic laboratory, and a room for storing and handling small quantities of radioactive isotopes.

The ground floor contains a number of private staff rooms and offices; but research laboratories comprise the greater part of this floor also. Most of the research in progress on this floor is devoted to the experimental study of electronic and ionic collisions. Systematic investigations are in progress on the exchange of charge or excitation, on ionization, and on elastic scattering produced when beams of ions or metastable atoms are passed through gases. Extensive work is also concerned with collision processes in atomic hydrogen and with studies of gaseous discharges. Gas, water, compressed air and oxygen services are installed throughout the ground and lower ground floors, as well as an adequate supply of d.c. and a.c. (both single- and three-phase) points.

The top floor, in addition to providing office accommodation for members of the staff and for research students specializing in theoretical physics, houses the departmental library, a small lecture room used particularly for seminars, and the computing laboratory. An electronic computer designed by Dr. A. D. Booth, of Birkbeck College, is now being installed in the computing laboratory. In addition to providing for the needs of the theoretical research in the Department, it is intended that when fully in operation the facilities of this machine will be made available to other departments of the College and University.

The number of research workers in the Physics Department at University College is large. There are some fifty postgraduate Ph.D. students, while there are altogether 78 research workers in the Department. Only some of these are accommodated in the new wing, however. The research groups working on the high-pressure cloud chamber, high-energy nucleon scattering and the electron lens 
for electron and positron scattering are still housed in temporary quarters. It is hoped that eventually all the rest of the research work of the Department as well as the workshop and lecture theatres will be accommodated in an adjacent building under conditions as satisfactory as those of the new wing.

\section{THE PHARMACEUTICAL SOCIETY}

$\mathrm{O}$

$\mathrm{N}$ May 23, the Pharmaceutical Society of Great Britain held a reception to mark the granting of its new constitution. Founded in 1841, the Society received a Royal Charter in 1843. Modifications were afterwards made in its constitution by the various Pharmacy Acts. A Supplemental Charter granted in 1953, virtually replacing the original, and the Pharmacy Act 1953 have now brought the Society's constitution into line with present-day circumstances and needs. A reception was held at 66 Portland Place, W.1, through the kindness of the Royal Institute of British Architects, to mark the occasion, and H.R.H. the Duke of Edinburgh attended the reception and was presented during the evening with his diploma as the first Honorary Fellow of the Society.

The Society's charters and grant of arms were on view, together with rare books from the Society's Library. Incunabula were represented by the "Latin Herbarius" printed at Passau in 1485, and the 1491 edition of the " $(\mathrm{H})$ ortus Sanitatis" from the press of Jacob Meydenbach at Mainz. The latter, a treatise on herbs, animals, birds, fishes, stones and minerals, showed the illustration of the Bausor tree, believed to exhale a narcotic poison. In the illustration two men lie beneath its branches, apparently in the sleep of death. Manuscripts included an early recipe book in Elizabethan hand and a fine English medical work of the seventeenth century, bound in contemporary calf. A copy of the second issue of the first "London Pharmacopoia" of 1618 published in December of that year attracted much interest. 'The first issue was published in May, but it was so full of errors that all copies were officially destroyed; a facsimile of it was exhibited. The first quarto edition, published in 1699, of the well-known satirical poem "The Dispensary", by Dr. Samuel Garth, dealing with the quarrels between the Society of Apothecaries and the Royal College of Physicians, was also on view.

At the request of the Duke of Edinburgh, an exhibition had been staged to portray the pharmaceutical industry's contribution to medical and veterinary science.

Featured on twenty large panels, arranged by the Association of the British Pharmaceutical Industry, was a representative selection of the drugs discovered and developed in recent years, which have revolutionized the practice of medicine and have made a significant contribution to advances in surgery.

In an introductory panel, some statistics of the industry were shown graphically. Its production, valued at $£ 19$ million in 1935 , had risen to $£ 120$ million in 1954. The numbers of persons employed by the industry in research, development, manu. facture both primary and secondary, and in distribution to the pharmacist, doctor and hospital, had risen much less than proportionately-from 22,000 in 1935 to 53,000 in 1951. Its exports, valued at $£ 3.28$ million in 1938 , amounted in value to $£ 33.6$ million in 1954.
The tendency to think of modern medicine in terms of sulphonamides, antibiotics and other recently discovered life-saving drugs often leads to the supposition that symptomatic treatment no longer has a place in medicine. As a reminder that preparations of vegetable drugs and their active principles are still used in considerable though steadily diminishing amounts, a panel was included featuring a flow chart of the manufacture of a galenical, photographs of fields of henbane, foxglove (digitalis) and deadly nightshade (belladonna), together with specimens of an opium poppy capsule, gentian root, nux vomica seeds, ergot sclerotia, and preparations of digitalis. Roots of Rauwolfia serpentaria and its principal alkaloid reserpine, now much used for mild hypertension and psychotic disorders, were also shown. The commercial development of the synthesis of atropine and the tropane alkaloids was illustrated by a photograph of the British plant now used for this purpose.

The developments in anæsthesia since Sir James Young Simpson introduced the use of chloroform in Edinburgh in 1847 were exemplified by the newer anæsthetics such as cyclopropane, trichloroethylene (including its application by self-administration) and thiopentone (used intravenously).

Muscle relaxants, which have a temporarily paralysing action and greatly facilitate modern surgery by avoiding the need for almost toxic doses of anæsthetic, derive their application from the isolation of the alkaloid tubocurarine from the South American arrow poison, curare. Poison-tipped darts and blowpipe, crystalline curare and a curare gourd prefaced specimens of tubocurarine and the more recently developed synthetic analogues, gallamine triethiodide and laudexium methylsulphate.

The development of specialized contrast media by the British pharmaceutical industry has enabled the medical use of X-rays to be extended, and in addition to the detection of bone fractures they now aid the radiologist to give a prominent picture of the gallbladder, arteries, bronchial tree, the urinary tract and other systems and organs. Among the radiological agents displayed were barium sulphate for preparation of barium meals, diodone, iodized oil, propyliodone, iodoxyl and ethyl iodophenylundecylate.

The use of injectable fluids to restore blood volume in cases of patients suffering from shock and loss of blood, as an alternative to the transfusion of blood, began with the discovery of the value of gum acaciasaline injection during the First World War. Dextran and polyvinylpyrrolidone were exhibited as newer agents which avoid the adverse effects of acaciasaline on the blood and liver. They are polymers of sufficiently high molecular weight not to be excreted too quickly.

The antibiotics formed the subject of two panels and exhibits. A photograph of the late Sir Alexander Fleming fittingly introduced the panels, which included a flow chart of penicillin manufacture, a chart depicting the rate of growth of manufacture and export of penicillin and its preparations, and another showing the estimation of sensitivity of organisms to antibiotics. Specimens shown of the different forms of presentation of penicillin included vials of penicillin $\vec{G}$ for preparation of the injection, of procaine penicillin, of oral suspension, tablets and ointment, and of penethamate hydriodide and benethamine penicillin. Specimens were also shown of streptomycin sulphate, chloramphenicol capsules, aureomycin, oxytetracycline, tyrothricin lozenges, polymixin-bacitracin ointment, neomycin, viomycin, 